\title{
Refractive status of primary school children in Mopani district, Limpopo Province, South
}

\section{Africa}

\section{RG Mabaso*, AO Oduntant, and MBL Mpolokengt†}

\author{
*,†'Department of Public Health, University of Limpopo, Turfloop Campus, P. Bag x1106, Sovenga \\ 0727, South Africa
}

'Department of Optometry, University of Limpopo, Turfloop Campus, P. Bag X1106, Sovenga, 0727, South Africa

\footnotetext{
*<mabaso@mweb.co.za>

†<alabio@ul.ac.za>

†>mpolokengm@ul.ac.za>
}

\section{Abstract}

This article reports part of the findings of a study carried out to determine the causes, prevalence, and distribution of ocular disorders among rural primary school children in Mopani district of Limpopo Province, South Africa. Three hundred and eighty eight children aged 8 to 15 years were randomly selected from five randomly selected schools. Non-cycloplegic retinoscopy and auto-refraction were performed on each child. The prevalence of hyperopia, myopia, and astigmatism was $73.1 \%, 2.5 \%$ and $31.3 \%$ respectively. Hyperopia (Nearest spherical equivalent power $\left(\mathrm{F}_{\mathrm{NSE}}\right)$ ranged from +0.75 to $+3.50 \mathrm{D}$ for the right and left eyes with means of +1.05 $\pm 0.35 \mathrm{D}$ and $+1.08 \pm 0.34 \mathrm{D}$ respectively. Myopia $\left(\mathrm{F}_{\mathrm{NSE}}\right)$ ranged from -0.50 to $-1.75 \mathrm{D}$ for the right eye and -0.50 to $-2.25 \mathrm{D}$ for the left eye with means of $-0.75 \pm 0.55 \mathrm{D}$ and $0.93 \pm 0.55 \mathrm{D}$ respectively. Regression model for myopia, shows that age had an odds ratio of 1.94 (1.15 to 3.26), indicating a significant increased risk of myopia with increasing age. Correcting cylinders for the right eyes ranged from -0.25 to $-4.50 \mathrm{D}$ (mean $=-0.67$ $\pm 0.47 \mathrm{D})$ and for the left eyes from -0.25 to $-2.50 \mathrm{D}$ (mean $=-0.60 \pm 0.30 \mathrm{D})$. With-therule (WTR) astigmatism (66.5\%) was more common, followed by against-the-rule (ATR) astigmatism (28.1\%) and oblique (OBL) astigmatism (5.4\%). With-the-rule astigmatism was more common in females than males; ATR astigmatism and OBL astigmatism were common in males. Regular vision screening programmes, appropriate referral and vision correction in primary schools in Mopani district are recommended in order to eliminate refractive errors among the children.

Keywords: Refractive error, hyperopia, myopia, astigmatism.

\footnotetext{
B.Optom FOA (SA) CAS (NewEnCO)

$\dagger$ BSc (Hon) Optom PhD

ते $\mathrm{MD} \mathrm{MPH}$
}

This article is part of a mini-dissertation submitted by RGM (supervised by AOO and MBLM) to the University of Limpopo, Turfloop Campus, South Africa, in partial fulfilment of the requirement for the degree of Master of Public Health (MPH) 


\section{Introduction}

It has been estimated that 2.3 billion people worldwide have refractive error, but only 1.8 billion people have access to eye examinations and affordable correction. This leaves approximately 500 million people (including children), mostly in developing countries (about $1 / 3$ in Africa), with uncorrected refractive error causing avoidable blindness and impaired vision ${ }^{1}$. In view of the increasing realization of the enormous need for correction of refractive error worldwide, this condition has been considered one of the priorities of the global initiative for the elimination of avoidable blindness: Vision 2020 - The Right to Sight, which was launched in 1999 by a coalition of nongovernmental organizations and the World Health Organization ${ }^{2}$. Undetected or under corrected refractive error, particularly myopia, is a problem among school children. This is because poor vision and inability to read what is written on the chalkboard can have a serious impact on children's participation in class and this can negatively affect the children's education, occupation, and socio-economic status for life ${ }^{3}$.

The impact of visual impairment due to myopia is not the same as that from hyperopia. This is because people who suffer from myopia are likely to have better near vision than those who suffer from hyperopia. Hyperopia, however, has been thought to be the cause of poor reading as sufferers have trouble forcing their eyes to focus on near tasks, so they are more susceptible to eye strain, headaches and blurred vision when reading. Hyperopes may often not understand what they are reading as more energy is expended to keep the text clear ${ }^{4}$.

Avoidable visual impairment due to uncorrected refractive error starts at a younger age if compared to avoidable visual impairment for example due to cataracts, which manifests at an older age ${ }^{5}$. It follows that an individual who is visually impaired due to uncorrected refractive error would suffer more years of dysfunction than the one who is visually impaired due to cataract. Visual impairment in children poses particular challenges that are different from those of adults. Children are born with an immature visual system and for normal visual development to occur; they need clear images to be focussed on the retina. Failure of normal visual maturation cannot be corrected in adult life; so, early detection and compensation of refractive errors will undoubtedly have a positive effect on children's education and life in general ${ }^{6}$.

There are reports on refractive errors in children that have been carried out in developing countries. In the rural population of India, myopia in one or both eyes was present in $4.1 \%$ of the children. Myopia risk was associated with female gender and having a father with higher level of schooling. Hyperopia in at least one eye was present in $0.8 \%$ of the children ${ }^{7}$. In a study conducted in New Delhi, India, the prevalence of hyperopia $(7.7 \%)$ was the highest, followed by myopia $(7.4 \%)$ and amblyopia $(4.4 \%)^{8}$.

Vision screening performed around Kuala Lumpur, Malaysia in 1990, to assess the prevalence of visual disorders in Chinese school children found that the prevalence of myopia -0.50 $\mathrm{D}$ or greater and hyperopia $+0.50 \mathrm{D}$ or greater was $42 \%$ and $14 \%$, respectively. No significant difference was found between myopia in males and females. Myopia was more common among Chinese school children than among Malays and other ethnic groups ${ }^{9}$. In a study carried out in Gombark District, Malaysia, next Kuala Lumpur, the prevalence of myopia $(-0.50 \mathrm{D}$ or greater) in either eye was $9.8 \%$ in children 7 years of age, increasing to $34.4 \%$ in 15 -yearolds. Myopia was associated with older age, female gender, Chinese ethnicity, and higher parental education. Hyperopia $(+2.00 \mathrm{D}$ or greater) varied from 3.8\% in 7-year-olds to less than $1 \%$ by age 15 . Hyperopia was associated with younger age. The prevalence of astigmatism was present in $15.7 \%$ of the children ${ }^{10}$.

A refractive error study among school-age children to assess the prevalence of refractive error and visual impairment in Shunyi district, North East of Beijing, China, found refractive error was the cause in $89.5 \%$ of the eyes with reduced visual acuity, amblyopia in 5\%, and other causes in $15 \%$ with unexplained causes in the remaining 4\%. Myopia $-0.50 \mathrm{D}$ or greater in either eye was essentially absent in five year olds, but increased to $36.7 \%$ in males and $55 \%$ in females by age 15 . Over the same age range, hyperopia, $+2.00 \mathrm{D}$ or greater decreased from $8.8 \%$ in males and $19.6 \%$ in females to less than $2 \%$ in both males and females. Females had a significantly higher risk 
of both myopia and hyperopia than males ${ }^{11}$.

A study to determine the prevalence, type, and progression of astigmatism in Chinese preschool children conducted by Fan et al ${ }^{12}$ found astigmatic error of $-0.50 \mathrm{D}$ or greater in $55.8 \%$ of the children, $-1.00 \mathrm{D}$ or greater in $21.1 \%$ and $2.2 \%$ and error of $-2.00 \mathrm{D}$ or greater was present in $2.2 \%$ of the subjects. Distribution of with-the-rule (WTR), against-the-rule (ATR), and oblique (OBL) astigmatism was $53.0 \%$, $7.9 \%$, and $39.1 \%$ respectively. In a Suburban area of Santiago, Chile, myopia $-0.50 \mathrm{D}$ or greater in either eye was present in $3.4 \%$ of five year old children, increasing to $19.4 \%$ in males and $14.7 \%$ in females by age 15 . Over the same age range, hyperopia of $+2.00 \mathrm{D}$ or greater decreased from $22.7 \%$ to $7.1 \%$ in males and from $26.3 \%$ to $8.9 \%$ in females. Females had a higher risk of hyperopia than males ${ }^{13}$.

A survey of the prevalence of refractive error among lower primary school children in Kampala district, Uganda, found the prevalence of refractive error to be $11.6 \%$. Astigmatism (52\%) was the most prevalent refractive error, followed by hyperopia (37\%) and myopia $(11 \%)^{14}$.

Despite the reported prevalence of vision problems in school children and the grave consequences that go with such problems, very few reports concerning this issue have been published in South Africa. In a retrospective study of refractive status of a South African black sample, conducted by Raliavhengwa and Oduntan ${ }^{15}$, myopia (48.15\%) was found to be more common than hyperopia $(35.67 \%)$ and emmetropia (16.18\%). The occurrence of myopia was found to be higher $(51.3 \%)$ than hyperopia (32.4\%) in males; however, hyperopia was higher $(39.9 \%)$ than myopia $(38.4 \%)$ in females.

In a study conducted by Naidoo et al ${ }^{16}$, refractive error $(63.6 \%)$ was the main cause of the visual disorders in Durban. The prevalence of hyperopia, myopia, and astigmatism was reported to be $2.6 \%, 4 \%$, and $9.2 \%$ respectively). Other than these two, no recent reports of the refractive status among children in South Africa could be found in the literature.

The purpose of this study was to investigate the refractive status of rural primary school children in the Mopani district of Limpopo Province. Findings from this study will help from an informed position to make appro- priate recommendation relating to intervention programs to the Provincial Government. In addition, early detection and compensation of refractive error would reduce the impact of visual impairment among the children.

\section{Method}

The proposal to conduct this study was approved by the Ethics Committee of the University of Limpopo, Turfloop Campus. The consent form was given to every eligible child for parental consent. Also, permission to carry out the study was obtained from the Department of Education, Limpopo Province. Three hundred and eighty eight black South African children of both sexes were examined. The sample size was calculated to estimate an anticipated $20 \%$ prevalence $(\rho)$ of refractive error within an error bound (B) of $20 \%$ with $95 \%$ confidence interval $(Z)$. The calculated sample size requirement for the study was 384 , from the formula: $\mathrm{N}=\mathrm{Z}^{2}(\boldsymbol{\rho})(1-\rho) / \mathrm{B}^{2}$. Five primary schools were randomly selected from a list of all schools present in the district. Also, the children were randomly selected using systematic sampling from the five schools. Unaided visual acuity was measured with a LogMAR illiterate chart $^{17}$. The refractive errors were measured by retinoscopy and auto-refraction. To assess the validity of the tests included in the study, sensitivity and specificity of the tests were calculated based on the values obtained from the test and re-test procedures done on 40 subjects using the following formulae:

Sensitivity $=\mathrm{TP}$

\section{$\mathrm{TP}+\mathrm{FN}$}

Specificity $=\underline{\mathrm{TN}}$

$\mathrm{TN}+\mathrm{FP}$

Where $\mathrm{TP}=$ true positive, $\mathrm{FP}=$ false positive, $\mathrm{TN}$ $=$ true negative, $\mathrm{FN}=$ false negative. Sensitivity of the tests was $100 \%$ and Specificity was $78.6 \%$. Based on these findings, the tests were considered to be reliable and valid.

Myopia was defined as the Nearest Spherical Equivalent power $\left(\mathrm{F}_{\mathrm{NSE}}\right)$ of $-0.50 \mathrm{D}$ or greater, hyperopia $\left(\mathrm{F}_{\mathrm{NSE}}\right)$ as $+0.75 \mathrm{D}$ or greater, emmetropia was defined as $\mathrm{F}_{\mathrm{NSE}}$ of from -025 
to $+0.50 \mathrm{D}$ and astigmatism as a cylindrical correction of $-0.25 \mathrm{D}$ or greater. WTR astigmatism was defined as cylindrical axis of 30 degrees or less from the horizontal meridian, ATR astigmatism as cylindrical axis of 30 degrees or less from the vertical meridian, and OBL astigmatism as cylindrical axis of greater than 30 degrees from either the horizontal meridian or vertical meridian.

Data analysis was done using Statistical Package for Social Sciences (SPSS), Statistical Analysis System (SAS), and Microsoft Excel software packages. Auto-refraction results were found to give more minus power which were unreliable and inconsistent. The differences between the retinoscopy and autorefraction were as high as $-1.50 \mathrm{D}$, and in every case, the auto-refractor gave more minus values. The auto-refractor data were therefore discarded. Thus the data analyzed and reported here are those of the retinoscopy.

\section{Results}

The subjects included in the study were 388 black primary school children. They included 193 (49.7\%) males and 195 (50.3\%) females. Their ages ranged from 8 to 15 years with a mean of $11.72 \pm 1.66$ years. Most of the subjects, $368(94.8 \%)$ were between the ages of nine and fourteen years. There were seventeen $(4.4 \%)$ children aged fifteen and only three $(0.8 \%)$ were eight years old.

\section{Visual acuities}

The percentage of eyes with unaided visual acuity (UVA) of $6 / 6$ or better was $88.3 \%$, and only $3.1 \%$ had unaided visual acuity of $6 / 10$ or worse. Of the $3.1 \%$ of the subjects with UVA of $6 / 10$ or worse, $99.5 \%$ improved to $6 / 7.5$ or better with pinhole and retinoscopic corrections. There were no subjects who wore spectacles; hence, no results for aided visual acuities are given.

\section{Refractive Errors}

Nearest spherical equivalent power ( $\left.F_{\mathrm{NSE}}\right)$

In the total sample, $566(72.9 \%)$ eyes had hyperopia and only $19(2.5 \%)$ had myopia. Others $191(24.6 \%)$ had emmetropia. $\mathrm{F}_{\mathrm{NSE}}$ for the right eyes ranged from -1.75 to $+3.50 \mathrm{D}$ (mean $=0.88 \pm 0.52 \mathrm{D}$, median $=+1.00 \mathrm{D}$ and

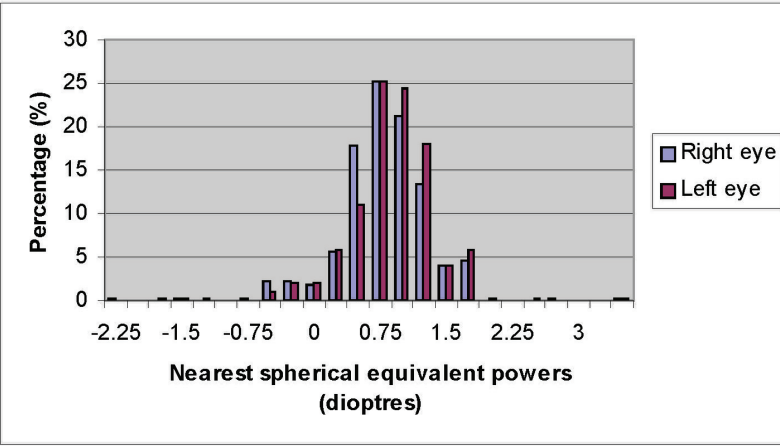

Figure 1 Frequency distribution of the nearest spherical equivalent powers $\left(\mathrm{F}_{\mathrm{NSE}}\right)$ among the subjects. The graph peaks at $25 \%$ and most of the powers were between +0.75 and $+1.75 \mathrm{D}$.

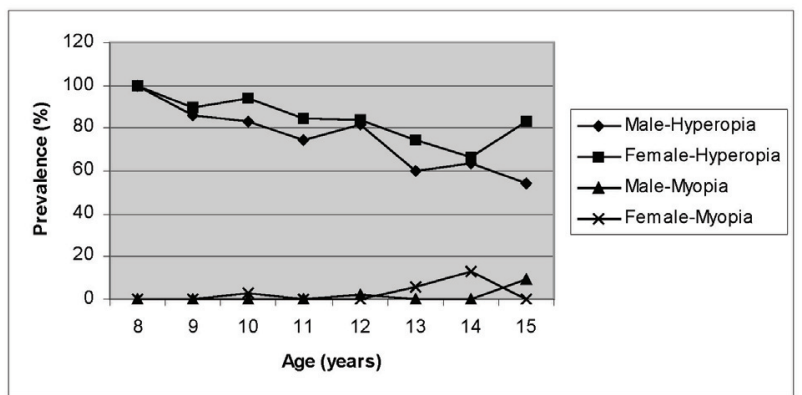

Figure 2 Graphical representation of the prevalence of refractive powers by age in the right eyes of the male and female subjects. Hyperopia was more prevalent in both genders.

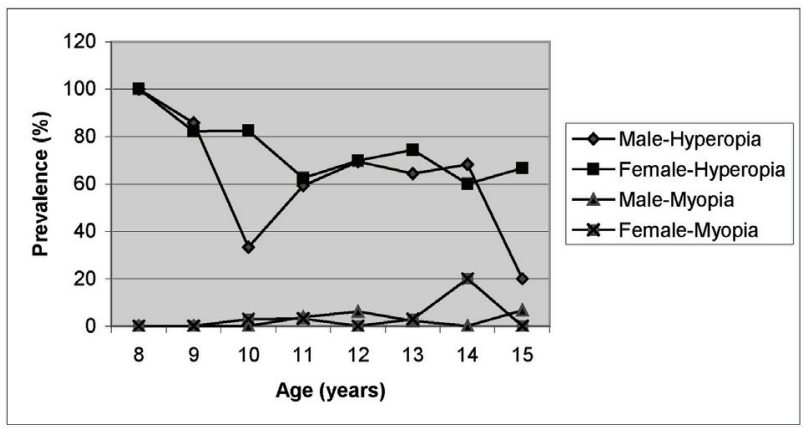

Figure 3 Graphical representation of the prevalence of refractive powers by age in the left eyes of the male and female subjects. Hyperopia was more prevalent in both genders.

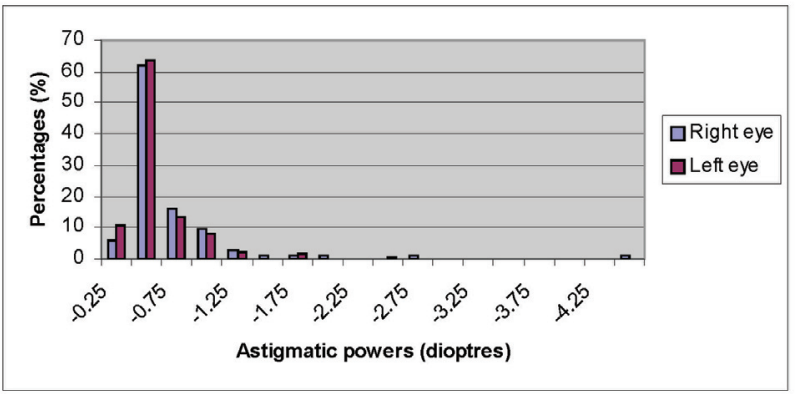

Figure 4 Graphical representation of the distribution of the cylindrical powers in the right and left eyes of the subjects. The graph peaks at $60 \%$ and most powers were $\leq 1.25 \mathrm{D}$. 
mode $=+1.00 \mathrm{D})$. For the left eyes, the range was from -2.25 to $+3.50 \mathrm{D}$ (mean $=0.80 \pm$ $0.53 \mathrm{D}$, median $=+0.75 \mathrm{D}$ and mode $=+0.75$ D). The NSE powers for all the eyes ranged from -2.25 to $+3.00 \mathrm{D}$ (mean $=0.84 \pm 0.52$ ) D. Hyperopia (NSE) ranged from +0.75 to $+3.50 \mathrm{D}$ for both the right and left eyes with means of $+1.05 \pm 0.35 \mathrm{D}$ and $+1.08 \pm 0.34$ $\mathrm{D}$ respectively. Myopia (NSE) ranged from -0.50 to $-1.75 \mathrm{D}$ for the right eye and -0.50 to $-2.25 \mathrm{D}$ for the left eye with means of -0.75 $\pm 0.55 \mathrm{D}$ and $-0.93 \pm 0.55 \mathrm{D}$ respectively.

The frequency distributions of NSE powers in the right and left eyes are shown in Figure 1 . The curve peaks at $+0.75 \mathrm{D}(25 \%)$ and is skewed toward the hyperopic side with a greater area under the curve in the region of +0.50 to +1.50 D. Powers of $+0.75 \mathrm{D}$ or less were more common in the left than the right eyes; and powers of $+1.00 \mathrm{D}$ or greater were more common in the right than the left eyes.

Nearest spherical equivalent powers $\left(F_{\text {NSE }}\right)$ and age

The prevalence of hyperopia was higher than that of myopia both in the right and left eyes of males and females among all age groups (Figures 2 and 3). Hyperopia (NSE, $+0.75 \mathrm{D}$ or greater) decreased from $100 \%$ among the 8 year olds to $53.1 \%$ among the 15 year olds. Myopia (NSE, -0.50 D or greater) increased from $1.7 \%$ among the 10 year old to $6.8 \%$ among the 14 year old group.

The means of $\mathrm{F}_{\mathrm{NSE}}$ for the right eyes decreased from $+1.50 \mathrm{D}$ in the 8-year-olds to $+0.59 \mathrm{D}$ in the 15-year-old subjects. For the left eyes, the means decreased from $+1.42 \mathrm{D}$ in the 8 -yearolds to $+0.53 \mathrm{D}$ in the 15 -year-olds. The difference between the powers on the right and left eyes was statistically insignificant ( $F$-test, $p=0.298)$. Hyperopia (73.1\%) was more prevalent than myopia $(2.5 \%)$ or emmetropia $\left(\mathrm{F}_{\mathrm{NSE}}\right.$, -0.25 to +0.50 D) $(24 \%)$. Using logistic regression to assess the relationship between age and prevalence of hyperopia, age had an odds ratio (OR) of 0.73 ( $95 \%$ CI, 0.63 to 0.85$)$, reflecting a decreased risk of hyperopia with increasing age. The association of hyperopia with age was statistically significant $(p=0.00)$. In a regression model for myopia, age had an odds ratio of 1.94 (1.15 to 3.26), indicating a significant increased risk of myopia with increasing age. Children aged $12-15$ years (OR, 2.29; 95\% CI, 1.09 to 4.81 ) had 1.4 times higher risk of myopia than those aged $8-11$ years (OR, 0.91; 95\% CI, 0.09 to 9.38 ) old. The association of myopia with age was statistically significant $(p=0.00)$.

Nearest spherical equivalent powers ( $\left.F_{\mathrm{NSE}}\right)$ and gender

Hyperopia, 302 (77.4\%) eyes was more common in females than in males 264(68.4\%); while $2.8 \%$ and $2.1 \%$ eyes respectively had myopia. Emmetropia was more common in males $(29.2 \%)$ than females $(19.8 \%)$ (see Table 1 and 2). The prevalence of myopia was $0 \%$ in 8,9 ,

\section{Table 1}

Distribution of the low, medium and high positive refractive powers $\left(\mathrm{F}_{\mathrm{NSE}}\right)$ among the male and female subjects (percentages in brackets). Most of the powers were $\leq+2.00 \mathrm{D}$.

\begin{tabular}{|l|l|l|l|}
\hline & \multicolumn{2}{|c|}{ HYPEROPIA } & \\
\hline $\begin{array}{l}\text { Nearest spherical equiva- } \\
\text { lent powers }\end{array}$ & Male & Female & Total \\
\hline $\begin{array}{l}+0.75 \text { to }+2.00 \\
\text { (Low hyperopia) }\end{array}$ & $262(46.6)$ & $300(53.4)$ & 562 \\
\hline $\begin{array}{l}+2.25 \text { to }+5.00 \\
\text { (Medium hyperopia) }\end{array}$ & $2(50)$ & $2(50)$ & 4 \\
\hline $\begin{array}{l}>+5.00 \mathrm{D} \\
\text { (High hyperopia) }\end{array}$ & 0 & 0 & 0 \\
\hline Total & $264(46.6)$ & $302(53.4)$ & $566(100)$ \\
\hline
\end{tabular}

Table 2

Distribution of low, medium and high negative refractive powers (FNSE) among the male and female subjects (percentages in brackets). All the powers were low myopia types $\leq-3.00 \mathrm{D}$.

\begin{tabular}{|l|l|l|l|}
\hline & \multicolumn{2}{|c|}{ MYOPIA } & \\
\hline $\begin{array}{l}\text { Nearest spherical equiva- } \\
\text { lent powers }\end{array}$ & Male & Female & Total \\
\hline $\begin{array}{l}-0.50 \text { to }-3.00 \\
\text { (Low hyperopia) }\end{array}$ & $8(42.1)$ & $11(57.9)$ & 19 \\
\hline $\begin{array}{l}-3.25 \text { to }-6.00 \\
\text { (Medium myopia) }\end{array}$ & 0 & 0 & 0 \\
\hline $\begin{array}{l}>-6.00 \mathrm{D} \\
\text { (High myopia) }\end{array}$ & 0 & 0 & 0 \\
\hline Total & $8(42.1)$ & $11(57.9)$ & 19 \\
\hline
\end{tabular}

10 -year-old males and $6.7 \%$ in the 15 -year-old male children, and increased from $0 \%$ in 8 and 9- year-old females to $20 \%$ in the 14 -year-olds. In the left eyes, there was no steady decrease in hyperopia or increase in myopia in males and females with increasing age. The prevalence of spherical refractive error by age in male 
and female subjects is shown in Figure 2 (for the right eyes) and Figure 3 (for the left eyes)

Among males and females, low hyperopia $(+0.75$ to +2.00 D) $(99.3 \%)$ was more common than medium $(+2.25$ to +5.00$)(0.01 \%)$ and high $(+5.00 \mathrm{D}$ or greater) $(0 \%)$ hyperopia. All the subjects with myopia had low myopia ( -0.50 to -3.00 D). Low hyperopia and low myopia were more common than other magnitudes (medium and high) of spherical errors. The distributions of the various magnitudes of refractive powers are shown in Table 1 (for hyperopia) and Table 2 (for myopia).

Many, $262(99.2 \%)$ of the hyperopia in males were of low magnitude, others, two $(0.8 \%)$ were medium. Among the females, many, 300 (99.3\%) of the hyperopia were of low magnitude. Others $(0.7 \%)$ were medium types (see Table 1$)$. Among the males, all (8) the myopia were low magnitude types and among the females, all (11) the myopia were of low magnitude (see Table 2).

The mean refractive error for males and females was $+1.02 \pm 0.48 \mathrm{D}$ and $+1.06 \pm 0.44$ $\mathrm{D}$ respectively. Among males (right eyes), the prevalence of hyperopia was $100 \%$ in 8 -yearolds and $54.5 \%$ in the 15 -year-olds. In 8-year-old females (right eyes), the prevalence of hyperopia was also $100 \%$ and $83.3 \%$ in the 15 -yearolds. The prevalence of myopia was $0 \%$ in 8 , 9, and 10-year-old males and $9.1 \%$ in the 15 year- old male children, and increased to $13 \%$ in the 14-year-olds. Among males (left eyes), the prevalence of hyperopia was $100 \%$ in 8-yearold and $20 \%$ in the 15-year-olds. In 8-year-old females (left eyes), the prevalence of hyperopia was also $100 \%$ and $66.7 \%$ in the 15 -year-olds.

Logistic regression used to assess the relationship between hyperopia prevalence and gender showed odds ratio for gender of $1.82(95 \%$ CI, 1.13 to 2.94). This reflects a higher risk for hyperopia in females. The association of hyperopia with gender was statistically significant $(p$ $=0.03$ ). The association between myopia and gender was not statistical significant $(p=0.15)$.

\section{Astigmatic powers}

Astigmatism occurred in $242(31.2 \%)$ of the eyes. The astigmatic powers for the right eyes ranged from -0.25 to $-4.50 \mathrm{D}$ (mean $=-0.67$ $\pm 0.48 \mathrm{D}$, median $=-0.50 \mathrm{D}$ and mode $=-0.50$ D). For the left eye it ranged from -0.25 to -2.50
$\mathrm{D}($ mean $=-0.60 \pm 0.30 \mathrm{D}$, median $=-0.50 \mathrm{D}$ and mode $=-0.50 \mathrm{D})$. The astigmatic powers for all eyes ranged from -0.25 to $-4.50 \mathrm{D}$ (mean $=0.63 \pm 0.39) \mathrm{D}$. The frequency distribution of astigmatic powers for the right and left eyes is shown in Figure 4. The curve peaks at $-0.50 \mathrm{D}$ and is skewed toward the medium to higher astigmatic powers. However, there is a greater area under the curve in the region of -0.25 and $-1.00 \mathrm{D}$.

Table 3

Distribution of astigmatic powers according to their magnitudes in the right and left eyes of the subjects. Most of the powers were of low magnitude $(-0.25$ to -0.75$)$.

\begin{tabular}{|l|l|l|}
\hline Astigmatic powers & Right eye & Left eye \\
\hline Low $(-0.25$ to $-0.75 \mathrm{D})$ & $88(83.8)$ & $120(87.6)$ \\
\hline $\begin{array}{l}\text { Medium } \\
(-1.00 \text { to }-3.00 \mathrm{D})\end{array}$ & $16(15.2)$ & $17(12.4)$ \\
\hline High (>-3.00D) & $1(1.0)$ & 0 \\
\hline Total & $105(100)$ & $137(100)$ \\
\hline
\end{tabular}

Table 4

Distribution of magnitudes of astigmatic powers (percentages in brackets) in the right and left eyes of the subjects. Low astigmatic powers were more common than the other categories.

\begin{tabular}{|l|l|l|l|l|l|l|}
\hline \multirow{2}{*}{$\begin{array}{l}\text { Cylindrical } \\
\text { Powers }\end{array}$} & \multicolumn{2}{|l|}{$\begin{array}{l}\text { Number of eyes } \\
\text { (Males) }\end{array}$} & \multicolumn{2}{|l|}{$\begin{array}{l}\text { Number of eyes } \\
\text { (Females) }\end{array}$} \\
\cline { 2 - 7 } & OD & OS & T o t a 1 & OD & OS & T o t a 1 \\
\hline $\begin{array}{l}-0.25 \text { to } \\
-0.75\end{array}$ & $\begin{array}{l}50 \\
(80.7)\end{array}$ & $\begin{array}{l}68 \\
(90.7)\end{array}$ & $\begin{array}{l}118 \\
(86.1)\end{array}$ & $\begin{array}{l}38 \\
(88.4)\end{array}$ & $\begin{array}{l}52 \\
(83.9)\end{array}$ & $\begin{array}{l}90 \\
(85.7)\end{array}$ \\
\hline $\begin{array}{l}-1.00 \\
-150\end{array}$ & $\begin{array}{l}10 \\
(16.1)\end{array}$ & $\begin{array}{l}6 \\
(8)\end{array}$ & $\begin{array}{l}16 \\
(11.7)\end{array}$ & $\begin{array}{l}4 \\
(9.3)\end{array}$ & $\begin{array}{l}8 \\
(12.9)\end{array}$ & $\begin{array}{l}12 \\
(11.4)\end{array}$ \\
\hline $\begin{array}{l}-1.75 \text { to } \\
-2.25\end{array}$ & $\begin{array}{l}1 \\
(1.6)\end{array}$ & 0 & $\begin{array}{l}1 \\
(0.7)\end{array}$ & $\begin{array}{l}1 \\
(2.3)\end{array}$ & $\begin{array}{l}2 \\
(3.2)\end{array}$ & $\begin{array}{l}3 \\
(2.9)\end{array}$ \\
\hline $\begin{array}{l}-2.50 \text { to } \\
-3.00\end{array}$ & 0 & $\begin{array}{l}1 \\
(1.3)\end{array}$ & $\begin{array}{l}1 \\
(0.7)\end{array}$ & 0 & 0 & 0 \\
\hline $\begin{array}{l}-3.25 \text { a } \mathrm{d} \mathrm{d} \\
\text { ove } \mathrm{r}\end{array}$ & 1 \\
$(1.6)$ & 0 & $\begin{array}{l}1 \\
(0.7)\end{array}$ & 0 & 0 & 0 \\
\hline To t a 1 & $\begin{array}{l}62 \\
(100)\end{array}$ & $75(100)$ & 137 & $\begin{array}{l}43 \\
(100)\end{array}$ & $\begin{array}{l}62 \\
(100)\end{array}$ & 105 \\
\hline
\end{tabular}

Table 5

Distribution of various types of astigmatism (according to their axes) in relation to gender. With - the-rule astigmatism $(66 \%)$ was more common than the other types.

\begin{tabular}{|l|l|l|l|}
\hline $\begin{array}{l}\text { Type of } \\
\text { astigmatism }\end{array}$ & $\begin{array}{l}\text { No. of eyes/ } \\
(\%) \text { Male }\end{array}$ & $\begin{array}{l}\text { No. of eyes/ } \\
(\%) \text { Female }\end{array}$ & Total \\
\hline WTR & $82(59.9)$ & $79(75.2)$ & 161 \\
\hline ATR & $47(34.3)$ & $21(20)$ & 68 \\
\hline OBL & $8(5.8)$ & $5(4.8)$ & 13 \\
\hline TOTAL & $137(100)$ & $105(100)$ & 242 \\
\hline
\end{tabular}

Low astigmatic powers were more common than medium and high astigmatic powers (Table 3). Powers of between -0.25 and $-0.75 \mathrm{D}$ (low astigmatic powers) were $83.8 \%$ and $87.6 \%$, 
for the right and left eyes respectively. Powers of between -1.00 and $-3.00 \mathrm{D}$ (medium astigmatic powers) were $15.2 \%$ and $12.4 \%$, for the right and left eyes respectively. Powers greater than $-3.00 \mathrm{D}$ (high astigmatic powers) were $1 \%$ and $0 \%$ for the right and left eyes respectively (Table 3). Astigmatic powers ranged from $0 \%$ among the 8-year-old to $50 \%$ among the 15 -year-olds. There was, however, no consistent increase in astigmatism with increasing age.

\section{Astigmatic powers and gender}

The prevalence of astigmatism was higher in males $(56.6 \%)$ than females $(43.4 \%)$. Low astigmatic powers were more common than medium and high astigmatic powers in both males and females. The prevalence of low and medium powers was similar in both male and female children. The occurrence of high power cylinders were uncommon in males $(1.5 \%)$, and absent in females (Table 4$)$.

\section{Types of astigmatism}

The prevalence of WTR astigmatism was the highest $(66.5 \%)$, followed by ATR astigmatism $(28.1 \%)$ and then by OBL astigmatism (5.4\%). WTR astigmatism was more common in females than males; ATR and OBL astigmatism were common in males than females (Table 5). There was no obvious relationship pattern between age and types of astigmatism.

\section{Discussion}

Uncorrected refractive errors and other ocular disorders can hinder education, personality development, and career opportunities, in addition they can cause economic burden on society. It is therefore, necessary that these disorders are detected and treated or corrected in time to avoid problems of ocular disorders. Also, in order for the health authorities to deliver proper eye care services to the communities, data on the prevalence of ocular disorders in children is needed. This study provides useful data to Mopani district municipality which will assist in planning for eye care service delivery.

Refractive errors were measured by noncycloplegic retinoscopy and auto-refraction. Only the retinoscopy results were analyzed.
This is because auto-refraction results were inconsistent and unreliable in certain cases. This observation agrees with reports by Naidoo and Govender ${ }^{18}$ that non-cycloplegic auto-refraction has limited role in vision screening in a paediatric population. The authors ${ }^{18}$ reported that even though the target has been set at infinity, the accommodative system does not remain at rest as previously assumed by researchers. The authors reckoned that it is possible that the nearness of the instrument target induces proximal accommodative response and instrument myopia. In the present study, there were differences as high as $-1.50 \mathrm{D}$ between retinoscopy and auto-refraction results; and in all cases, autorefraction results gave more myopia. This was attributed to the theory of proximal accommodative response and instrument myopia as previously suggested by Govender and Naidoo ${ }^{18}$.

The greater occurrence of hyperopia in the study is in agreement with the findings reported by several authors ${ }^{8,13,19,20,21}$. It is, however, at variance with the findings in other studies ${ }^{9}$, 11, 14-16 where the prevalence of myopia was greater than that of hyperopia. The differences may be attributed to the differences in the methods, definitions, and demographics in the various studies. For instance, in this study, non-cycloplegic retinoscopy was used to determine refractive error; hyperopia was defined as powers of $+0.75 \mathrm{D}$ or greater; and subjects were rural primary school children. In the other studies ${ }^{8,11,13,16}$, however, cycloplegic retinoscopy was used to determine refractive error; hyperopia was defined as powers of $+2.00 \mathrm{D}$ or greater, and subjects were schoolage children in both rural and urban settings.

There is a general agreement that the prevalence and distribution of refractive status varies greatly with age. Hyperopia was the most common refractive error in this study; with increasing age, however, there was a steady shift in the distribution of refractive error towards less hyperopia. The prevalence of myopia appeared to increase with age. The statistically significant association of hyperopia and myopia with increasing age observed in this study agrees with earlier reports ${ }^{10,11,13}$. This could be explained by the fact that younger subjects have smaller eyes hence the high prevalence of hyperopia among the younger subjects. The size 
of the eye increases with increasing age; hence increase in myopia prevalence with increasing age. This agrees with the views of Grosvenor ${ }^{22}$ that refractive error distributes normally at birth, but early in infancy, the majority of the children are found to be somewhat hyperopic, with a tendency toward myopia up to $20 \%$ or more in the 20 -year-old population.

In the present study, there was a statistically significant association between hyperopia and female gender. This finding agrees with the findings of Maul et al. ${ }^{13}$; Phokarel et al. ${ }^{21}$; Raliavhegwa and Oduntan ${ }^{15}$; and Raju et al. ${ }^{23}$ where hyperopia was more common in females than males, but disagrees with the findings of Ritchler and Bear ${ }^{24}$, where the contrary was the case. The association between myopia and gender (male and female) was not statistically significant.

That hyperopia was more common in females than males could be explained probably by the fact that females have smaller eyes than males as reported by Kondo et al. ${ }^{25}$. The higher prevalence of hyperopia in this study may further be explained by the greater number of females than males in the younger age group.

The prevalence of myopia $(2.5 \%)$ found in this study was low compared to $6.8 \%$ found in Chile ${ }^{13}, 16.2 \%$ in China $^{11}$ and $7.4 \%$ in New Delhi ${ }^{8}$. Higher level of education, better housing, and higher individual income has been associated with higher odds of myopia and higher degrees of myopia, after adjusting for age and $\operatorname{sex}^{26}$. Educational attainment of the father has also been found to be associated with increased risk of myopia among children aged 11 to 13 years (OR, 1.69; 95\%CI, 1.292.23 ), and 14 to 15 years (OR, $1.49 ; 95 \% \mathrm{CI}$, $1.17-1.90)^{8}$. That children in this study live in rural areas may explain the low prevalence of myopia. The children in rural areas probably do not engage in a lot of reading to the same extent as those in urban areas. Most households do not have access to electricity, so most, if not all reading must be done at school; hence few hours are spent reading.

The multi-country survey of refractive errors in children "The refractive error study in children (RESC)", conducted by the World Health Organization (WHO) in different regions revealed that there are significant geographical differences in the preva- lence of refractive errors. The prevalence of refractive errors in $\mathrm{Chile}^{13}$, China ${ }^{11}$, $\mathrm{Nepal}^{21}$, rural India ${ }^{7}$, New Delhi ${ }^{8}$ and Durban ${ }^{16}$, were $56.3 \%, 89.5 \%, 56 \%, 61 \%, 81.7 \%$ and $63.6 \%$, respectively. In the present study, the prevalence of refractive error was $76 \%$. However, direct comparisons with the above studies are not possible because of the differences in examination protocol and populations studied.

The prevalence of astigmatism in the present study $(31.3 \%)$ was lower than $34.8 \%$ reported by Wedner et al. ${ }^{27}$, but higher than the $2.8 \%$ reported by Dandona et al. ${ }^{7}, 2.2 \%$ by Phokarel et al. ${ }^{21}, 5.4 \%$ by Murphy et al. ${ }^{8} ; 19 \%$ by Maul et al. ${ }^{13} ; 15.7 \%$ by Goh et al. ${ }^{10}$ and $9.2 \%$ by Naidoo et al. ${ }^{18}$. Again, meaningful comparisons between these findings and data from previous studies are difficult because of differences in the methodology, definitions, and demographics in the various studies.

The lower prevalence of astigmatism in the younger group compared to the older group suggests an increase in the values of astigmatism with age. This agrees with the report by Raliavhengwa and Oduntan ${ }^{15}$, but disagrees with others ${ }^{8,11,13}$ who reported an association between astigmatism and younger age.

Studies on children samples have reported high prevalence of with-the-rule astigmatism while those of adults and aged population ${ }^{28}$ have reported that most of the subjects had againstthe-rule astigmatism. The changes associated with age may be explained by the hypothesis that eyelid tension is responsible for with-the-rule astigmatism by steepening the vertical corneal meridian and flattening the horizontal meridian ${ }^{29}$. The greater prevalence of with-the-rule astigmatism in this study is in agreement with previous reports ${ }^{12,19,22}$, but disagrees with others ${ }^{15,18,23}$ who reported greater prevalence of against-therule astigmatism in the populations studied. The differences in the age distribution of the subjects studied may have played a role in the differences in these reports. The subjects in Raliavhengwa and Oduntan ${ }^{15}$, and Raju et al. ${ }^{23}$ included more adults than younger subjects, in contrast to the study which included younger subjects only.

Astigmatism was more common in males than females in this study. This is in disagreement with report by Murphy et $a l .^{8}$ who reported greater prevalence of astig- 
matism in females than males. Differences in methods and population studied may be responsible for difference in the association between astigmatism and gender.

\section{Conclusion and recommendation}

Refractive error can be treated easily with spectacles and as such, the detrimental impact of visual impairment on a child's education and development could be prevented. Unfortunately, none of the children were wearing spectacles. Lack of eye care services, poor knowledge of vision problem awareness and cost of spectacles may be the reasons for children not wearing spectacles. Population-based vision screening or at least school screening in the rural communities of South Africa is, therefore recommended. The outcome of such interventions will improve the children's academic life and quality of life in general.

\section{References}

1. Holden BA. The challenge of providing spectacles in the developing world. Com Eye Health J 200013 9-10.

2. Holden BA, Resnikoff S. The role of Optometry in Vision 2020. Com Eye Health J 200215 33-66

3. Taylor HR. Refractive errors: magnitude of the need. Com Eye Health J 200013 1-2

4. Perrault E D. The effects of visual stress on eye movements and comprehension while reading. J Optom Vis Dev 199223 27-38.

5. Dandona R, Dandona L. Refractive error blindness. Bull WHO 200179 237-243.

6. Gilbert C, Foster A. Childhood blindness in the context of Vision 2020- The Right to Sight. Bull WHO 200179 227-232.

7. Dandona R, Dandona L, Srinivas M, Sahare P, Narsaiah S, Munoz SR, Pokharel GP, Ellwein LB. Refractive error in children in a rural population in India. Invest Ophthalmol Vis Sci 200243 615-622.

8. Murphy GVS, Gupta SK, Ellwein LB, Munoz SR, Pokharel GP, Sanga L, Bachant D. Refractive error in children in an urban population in New Delhi. Invest Ophthalmol Vis Sci 200243 623-631.

9. Chung KM, Mohidin N, Yeow PT, Tan LL. The prevalence of visual disorders in Chinese schoolchildren. $\mathrm{Op}$ tom Vis Sci 199673 695-700.

10. Goh P, Abgariyah Y, Pokharel GP, Ellwein LB. Refractive error, and visual impairment in school age children in Gombark district, Malaysia. Ophthalmol 2005112 678685.

11. Zhao J, Pan X, Sui R, Munoz SR, Sperduto RD, Ellwein LB. Refractive error study in children: Results from Shunyi district, China. Am J Ophthalmol 2000129 427-435.

12. Fan DSP, Rao SK, Cheug EY, Islam M, Chew S, Lam DSC. Astigmatism in Chinese preschool children: Prevalence, change, and effect on refractive development. $\mathrm{Br} J$
Ophthalmol 200488 938-941.

13. Maul E, Barroso S, Munoz SR, Sperduto RD, Ellwein LB. Refractive error study in children: results from $\mathrm{La}$ Florida, Chile. Am J Ophthalmol 2000129 445-454.

14. Kawuna M, Mayeku R. A survey of the prevalence of refractive errors among children in lower primary schools in Kampala district. Afr Health Sci 20002 69-72.

15. Raliavhegwa M, Oduntan AO. A retrospective study of the refractive status of a South African black population. S Afr Optom 200059 72-77.

16. Naidoo KS, Raghunandan A, Mashinge KP, Govender P, Holden BA, Pokharel GP, Ellwein LB. Refractive error and visual impairment in African children in South Africa. Invest Ophthalmol Vis Sci 200344 3764-3770.

17. Oduntan AO, Briggs ST. Design of a logMAR Distance visual acuity chart for young children and illiterate adults. Ophthal Physiol Opt 199919 431-437.

18. Naidoo KS, Govender P. A comparison of non-cycloplegic auto-refraction and cycloplegic refraction of African children aged 5-15 years in Kwazulu Natal. S Afr Optom 200564 11-17.

19. Gordon A. Refractive error in Puerto Rican rural population. J Am Optom Assoc 199061 40-43

20. Kalikivayi V, Naduvilath TJ, Bansal AK, Dandona L. Visual impairment in school children in Southern India. Indian J Ophthalmol 199745 129-134.

21. Pokharel GP, Negrel AD, Munoz SR, Ellwein LB. Refractive error study in children: Results from Mechi Zone, Nepal. Am J Ophthalmol 2000129 436-444.

22. Grosvener TP. Primary Care Optometry. 2nd ed. Chicago: Professional press, 1989 30-44.

23. Raju P, Ramesh S, Arvind H, George R, Baskaran M, Paul PG, Kumaramanickavel G, McCarthy C, Vijaya L. Prevalence of refractive errors in a rural South Indian population. Invest Ophthalmol Vis Sci 200445 4268-4272.

24. Ritchler A, Bear JC. The distribution of refraction in three isolated communities in Western Newfoundland. Am J Optom Physiol Opt 198057 861-871.

25. Kondo T, Miura M, Imamichi M. Anterior chamber volume in the normal eye. Acta Soc Ophthalmol Jpn 1985 89 1099-1103.

26. Wong TY, Foster PJ, Hee J, NG Tze, Tielsch JM, Chew SJ, Johnson GJ, Seah SK. Prevalence and risk factors for refractive errors in adult Chinese in Singapore. Invest Ophthalmol Vis Sci 200041 2486-2494.

27. Wedner SH, Ross J, Todd AA, Balira R, Foster A. Myopia in secondary school students in Mwanza City, Tanzania: The need for a national screening programme. $\mathrm{Br} J$ Ophthalmol 200286 1200-1206.

28. Lavery JR, Gibson JM, Shaw DE, Rosenthal AR. Refraction and refractive errors in an elderly population. $O p h$ thal Physiol Opt 19888 394-396.

29. Goss DA. Meridional analysis of with-the-rule astigmatism in Oklahoma Indians. Optom Vis Sci 198966 281287. 